\title{
Demographic and Mental Health Factors Associated with Pathological Dissociation in a Portuguese Sample
}

\author{
Helena Espirito Santo, MPsy, PsyD \\ José Luís Pio-Abreu, MD, PhD
}

\begin{abstract}
Pathological dissociation has been extensively studied in many countries; however, little is known about it in Portugal. This research examined the role of demographic variables and mental health on dissociation in Portugal. We assessed 505 participants from 6 samples consisting of dissociative patients $(n=37)$, conversive patients $(n=26)$, somaticizing patients $(n=59)$, posttraumatic stress disorder patients $(n=50)$, other psychiatric patients $(n=174)$, and nonclinical subjects $(n=159)$. Dissociation was measured by Portuguese versions of the Dissociative Experiences Scale and Somatoform Dissociation Questionnaire; the LEAD procedure and subscales of the Brief Symptom Inventory indicated mental health. Pathological psychological dissociation was significantly more frequent in women, in the youngest of the participants, and in those with less education. Multiple logistic regression revealed that psychoticism, paranoid ideation, and depression symptoms made both men and women more vulnerable to psychological dissociation. Furthermore, psychological dissociation was more probable in men having symptoms of obsession and paranoid ideation and in women having symptoms of psychoticism and
\end{abstract}

Helena Espirito Santo is affiliated with the Department of Psychology at Instituto Superior Miguel Torga in Portugal.

José Luís Pio-Abreu is affiliated with the Department of Psychiatry and Department of Psychotherapy at the Hospitais da Universidade de Coimbra in Portugal.

Address correspondence to: Dr. Helena Espirito Santo, Department of Psychology, Instituto Superior Miguel Torga, R. Augusta 46, 3000-061 Coimbra, Portugal (E-mail: espirito-santo@ismt.pt).

Journal of Trauma \& Dissociation, Vol. 9(3) 2008

Available online at http://jtd.haworthpress.com

(C) 2008 by The Haworth Press. All rights reserved. doi:10.1080/15299730802139238 
paranoid ideation. Pathological somatoform dissociation was significantly more probable in women with less education. Moreover, somatoform dissociation was more likely in women with somatization symptoms and more likely in men with symptoms of somatization and psychoticism. Even though significant associations were found, causal relations could not be established because the study was cross-sectional.

KEYWORDS. Pathological dissociation, Dissociative Experiences Scale, Somatoform Dissociation Questionnaire, assessment, demographic factors, mental health factors

\section{INTRODUCTION}

In the 19th century, Pierre Janet was the first to formulate a dissociation theory that postulated psychological and somatoform dissociation as hysterical reactions that consist of amnesia, intrusive traumatic memories, and sensory and motor alterations (Janet, 1889/1998; Nijenhuis, 2000). At the present time, dissociation is conceptualized as the disintegration of consciousness, memory, identity, and perception of the environment (American Psychiatric Association, 1994). Dissociation can be conveyed in psychological and in somatoform ways (Näring \& Nijenhuis, 2005; Nijenhuis, 2000; Nijenhuis, Spinhoven, Van Dyck, Van der Hart, \& Vanderlinden, 1996; Van der Hart, Van Dijke, Van Son, \& Steele, 2000; G. Waller et al., 2000). Both are mental phenomena, and the denominations merely state the ways in which dissociation can be expressed. Psychological dissociation is expressed in mental aspects, and somatoform dissociation is manifested in the body (Nijenhuis, 2000). The Dissociative Experiences Scale (DES; Bernstein \& Putnam, 1986) and Somatoform Dissociation Questionnaire (SDQ-20; Nijenhuis et al., 1996) were developed, respectively; these instruments are the most extensively employed self-report measures of dissociation and make possible comparisons between samples across the world.

The clinical significance of dissociation is widely recognized. Psychological dissociation is a key aspect of dissociative disorders (e.g., American Psychiatric Association, 1994; Carlson \& Putnam, 1993; Carlson et al., 1993), posttraumatic stress disorder (PTSD; e.g., Bremner et al., 1992; Loewenstein, 1991), and borderline personality disorder (e.g., Boon \& Draijer, 1991; Saxe et al., 1993; Shearer, 1994). In addition, high levels of psychological dissociation have been reported in somatoform disorders 
(e.g., Pribor, Yutzy, Dean, \& Wetzel, 1993; Saxe et al., 1994), mood disorders (e.g., Saxe et al., 1993) obsessive-compulsive disorder (e.g., Grabe et al., 1999), and eating disorders (e.g., Vanderlinden, Vandereycken, Van Dyck, \& Vertommen, 1993). Moreover, psychological dissociation is substantially associated with general psychopathology: general distress (Grabe et al., 1999; Walker, Katon, Neraas, Jemelka, \& Massoth, 1992), sexual abuse (G. Waller et al., 2000), symptoms of anxiety and depression (D. Baker et al., 2003), hostility, phobia, anxiety and somatization (Norton, Ross, \& Novoltny, 1990), psychoticism (Allen, Coyne, \& Console, 1996; Kennedy et al., 2004; H. Merckelbach, Rassin, \& Muris, 2000; Moskowitz, Barker-Collo, \& Ellson, 2005; C. Spitzer et al., 2006), paranoid ideation (Moskowitz et al., 2005), and symptoms of obsession (Grabe et al., 1999; Prueter, Schultz-Venrath, \& Rimpau, 2002; Rufer, Fricke, Held, Cremer, \& Hand, 2006).

Somatoform dissociation is also associated with dissociative disorders (e.g., Nijenhuis et al., 1996, 1999), PTSD, conversion disorders (Espirito Santo \& Pio Abreu, 2007), somatoform disorders, and eating disorders (Nijenhuis et al., 1999). Moreover, depression is associated with both high psychological and somatoform dissociation (Maaranen, Tanskanen, Kaisa, et al., 2005). Somatoform dissociation is related to general psychopathology; sexual abuse (Nijenhuis et al., 1999) and somatization (Nijenhuis et al., 1999) are positively related with dissociation.

Correlations between demographic factors and both types of dissociation are various and contradictory. Whereas some researchers have found that psychological dissociation does not differ between genders in the general population (Akyüz, Doğan, Sar, Yargic, \& Tutkun, 1999; Irwin, 1999; Ross, Joshi, \& Currie, 1990; Sar, Kundakçı, Kızıltan, Bakim, \& Bozkurt, 2000; Seedat, Stein, \& Forde, 2003; C. Spitzer et al., 2003, 2004), between various psychiatric populations (Baker et al., 2003; C. Spitzer et al., 2003; Tezcan et al., 2003; G. Waller et al., 2000), or between mixed populations (Grabe et al., 1999; C. Spitzer et al., 2006), others have shown higher levels of dissociation in women from the general population (Maaranen, Tanskanen, Honkalampi, et al., 2005) and in psychiatric inpatients (Tutkun et al., 1998). On the contrary, another investigation found more pathological dissociation in men (Seedat et al., 2003). The same discrepancies apply to somatoform dissociation: The majority of investigations have shown that gender does not have a significant effect on somatoform dissociation (Nijenhuis, 2000; Nijenhuis et al., 1996; Sar et al., 2000; G. Waller et al., 2000). Nevertheless, a number of investigators have found higher levels of dissociation in 
women than in men (El-Hage, Darves-Bornoz, Allilaire, \& Gaillard, 2002; Nijenhuis, Van der Hart, \& Kruger, 2002), whereas one study found the opposite-men showed more somatoform dissociation (Maaranen et al., 2004).

Correlations between each type of dissociation and age are also diverse: In some studies, psychological dissociation was found more frequently among younger participants (Dorahy, Lewis, Millar, \& Gee, 2003; Irwin, 1999; Maaranen, Tanskanen, Kaisa, et al., 2005; Näring \& Nijenhuis, 2005; Ross et al., 1990; Seedat et al., 2003; C. Spitzer et al., 2006; Tutkun et al., 1998; N. G. Waller \& Ross, 1997), whereas other studies did not show any significant correlation (Maaranen, Tanskanen, Honkalampi, et al., 2005; Sar et al., 2000; C. Spitzer et al., 2004; G. Waller et al., 2000). According to some research, somatoform dissociation is not associated with age (El-Hage et al., 2002; Näring \& Nijenhuis, 2005; Nijenhuis, 2000; Nijenhuis et al., 1996; G. Waller et al., 2000), whereas other investigations, and in contrast with psychological dissociation, have revealed a positive correlation between age and somatoform dissociation (Maaranen et al., 2004; Sar et al., 2000).

Some studies have shown a relationship between psychological dissociation and being single (Maaranen, Tanskanen, Kaisa, et al., 2005; Seedat et al., 2003; C. Spitzer et al., 2006). Somatoform dissociation is also associated with the subjects being single, divorced, or widowed (Maaranen, Tanskanen, Kaisa, et al., 2005). Finally, educational level has not shown any significant effect on psychological dissociation (Akyüz et al., 1999; Boon \& Draijer, 1991; Ross et al., 1990), except in one study (Dunn, Paolo, Ryan, \& Van Fleet, 1993), where a higher educational level was associated with a lower rate of dissociation. Similarly, the level of education was negatively correlated with somatoform dissociation (Maaranen et al., 2004; Sar et al., 2000).

Despite this continued interest, there are no published studies on dissociation in Portugal, and in Europe there are few studies on dissociation, especially when compared with the United States. For this reason, our study investigated the frequency of dissociation in different nonclinical and clinical samples and explored the factors that were independently associated with both types of dissociation after the measurement of the presence of psychopathological symptoms in various demographic characteristics. We examined the two forms of dissociation to fill the existing lacuna. 


\section{METHODS}

\section{Participants and Procedures}

A total of 346 clinical subjects were selected from diverse samples pertaining to other studies, and they were all recruited between 2002 and 2006 (Espirito Santo \& Pio Abreu, in press, 2006, 2007). We carried out a longitudinal evaluation of each patient. A "gold standard" was used to validate the clinical diagnoses through the LEAD procedure (R. L. Spitzer, 1983): a longitudinal evaluation by experts (a trained psychiatrist with 35 years of practice and a psychologist with 15 years of practice) was performed using all $d$ ata available (nonstructured clinical interviews, and ongoing clinical contact and all available clinical records). A total of 61 patients were evaluated with the Portuguese version of the Dissociative Disorders Interview Schedule for confirmation of the clinical diagnosis. All patients gave their informed consent both orally and in writing, according to the Code of Medical Ethics of the World Medical Association Declaration of Helsinki. Clinical subjects included 83 new referrals and 178 patients in regular care from three psychotherapeutic outpatient centers, and they were successively selected. The remaining 85 patients were receiving full-day treatment from a psychiatric inpatient unit and were consecutively selected from diagnostic referrals of a dissociative or somatoform disorder. Their mean age was 32.11 years $(S D=12.67$; range $=18-65)$; their clinical diagnoses according to Diagnostic and Statistical Manual of Mental Disorders (4th ed. [DSM-IV]; American Psychiatric Association, 1994) criteria were dissociative disorders, somatoform disorders (conversion and somatization), PTSD, depression disorders, and anxiety disorders.

The nonclinical sample, with an age range from 18 to $65(M=37.31$, $S D=12.00$ ), was recruited from students, colleagues, friends, and their relatives. The subjects received the results of the questionnaires when requested. This constituted a convenience sample, one not representative of the Portuguese population. The number of participants in each subsample and their demographic characteristics are shown in Table 1. Men and women did not differ significantly in age, $\chi^{2}(4)=5.88, p>.05, N=505$; marital status, $\chi^{2}(1)=2.39, p>.05, N=505$; or years of education, $\chi^{2}(4)=$ $7.61, p>.05, N=505$. All 505 participants completed the DES and SDQ20, and 421 participants also filled out a measure on psychopathology (i.e., Brief Symptom Inventory). 
TABLE 1. Demographic characteristics of subsamples.

\begin{tabular}{|c|c|c|c|c|c|c|c|}
\hline \multirow[t]{2}{*}{ Subsample } & \multirow[t]{2}{*}{$N$} & \multirow{2}{*}{$\begin{array}{c}\text { Age } \\
\text { (Years), } \\
M(S D)\end{array}$} & \multicolumn{2}{|c|}{ Gender, $n(\%)$} & \multicolumn{2}{|c|}{ Marital Status, $n(\%)$} & \multirow{2}{*}{$\begin{array}{l}\text { School } \\
\text { (Years), } M \\
(S D)\end{array}$} \\
\hline & & & Male & Female & Married & Single & \\
\hline Dissociative Disorders & 37 & $34.1(12.0)$ & $11(29.7)$ & $26(70.3)$ & $18(48.6)$ & $19(51.4)$ & $9.3(4.3)$ \\
\hline Posttraumatic Stress Disorder & 50 & $30.4(13.6)$ & $16(32.0)$ & $34(68.0)$ & $13(26.0)$ & $37(74.0)$ & $11.9(2.5)$ \\
\hline Conversion Disorder & 26 & $27.4(8.8)$ & $6(23.1)$ & $20(76.9)$ & $8(30.8)$ & $18(69.2)$ & $10.9(4.1)$ \\
\hline Somatization Disorder & 59 & $35.8(13.4)$ & $19(32.2)$ & $40(67.8)$ & $28(47.5)$ & $31(52.5)$ & $10.8(4.0)$ \\
\hline Anxiety and Depressive Disorders & 174 & $31.6(12.5)$ & $60(34.5)$ & $114(65.5)$ & $57(32.7)$ & $117(67.3)$ & $11.7(3.9)$ \\
\hline Nonclinical & 159 & $37.3(12.0)$ & $91(57.2)$ & $68(42.7)$ & $91(57.2)$ & $68(42.8)$ & $12.7(4.1)$ \\
\hline Total & 505 & $33.7(12.7)$ & $203(40.2)$ & $302(59.8)$ & $209(41.4)$ & $296(58.6)$ & $11.7(4.0)$ \\
\hline
\end{tabular}




\section{Instruments}

The DES is a self-administered 28-item questionnaire developed by Bernstein and Putnam (1986) for which individuals select the percentage of time that they experience certain events (from $0 \%$ to $100 \%$ ). The Portuguese version assesses psychological dissociation phenomena such as absorption, depersonalization-derealization, amnesia, and distractibility, which is a fourth factor found only in the Portuguese study. Its reliability and validity were comparable with other studies; the cutoff for pathological psychological dissociation was set at 30 (Espirito Santo \& Pio Abreu, in press).

The SDQ-20 assesses somatoform phenomena such as sensory disturbances, motor problems, analgesia, pain, anaesthesia, and loss of consciousness. It is a self-report tool consisting of 20 items (Nijenhuis et al., 1996). The reliability and validity of the Portuguese version were comparable to other studies, and the cutoff score for pathological somatoform dissociation was 35 (Espirito Santo \& Pio Abreu, 2007). The thresholds of the DES and SDQ-20 were used to select subjects for the statistical analysis.

The Brief Symptom Inventory is a 53-item self-report clinical rating scale that asks individuals to rate how distressed they have been over the previous 7 days through a list of psychopathological symptoms. In addition to an overall distress score (Global Severity Index), it includes nine symptom subscales: somatization, interpersonal sensitivity, anxiety, phobic anxiety, obsessive compulsion, depression, hostility, paranoid ideation, and psychoticism. The psychometric features of the Portuguese version were similar to those of the original version (Canavarro, 1988).

The Dissociative Disorders Interview Schedule is a structured interview developed by Ross et al. (1989). The Portuguese adaptation (Espirito Santo, Madeira, \& Pio Abreu, 2007) permits the recognition of $D S M-I V$ diagnoses of all dissociative disorders, somatization disorder, and conversion disorder (with a sensitivity rate of $84 \%$ and a specificity rate of $100 \%$ ).

\section{Statistical Analysis}

As scores for the DES and SDQ-20 deviated from a normal distribution, a usual finding in the literature (Bernstein \& Putnam, 1986), nonparametric statistical methods were used to analyze the data. Subjects with the five diagnoses were compared with one another according to the mean scores of dissociative experiences and the mean of the SDQ-20 
scores. The Kruskal-Wallis test was used, followed by post hoc MannWhitney tests on each pair of groups with the $p$ value adjusted by the Bonferroni method $(p<.0007)$. The mean Brief Symptom Inventory scores of the different demographic categories were compared through the Kruskal-Wallis test (values of this test are reported according to the results of testing the equality of variance assumption [Levene's test]). Multiple logistic regression analysis was carried out to find factors independently associated with high psychological and somatoform dissociation. Estimates were calculated using SPSS software (SPSS, Chicago, IL).

\section{RESULTS}

\section{Pathological Dissociation, Mental Health, and Demographic Variables}

In the total sample, the mean DES score was $19.8(S D=14.2$; range $=$ $0-72.9)$, and the mean SDQ-20 score was 29.7 ( $S D=9.8$; range $=20.0$ 76.0). Table 2 presents the mean scores and standard deviations of the DES and SDQ-20 of the various psychopathological groups. There were significant differences between the groups for the DES $(H=2468.8$; $p>.001)$ and SDQ-20 $(H=181.1 ; p<.001)$, except between dissociative and PTSD patients, dissociative and conversion disordered patients, and PTSD and conversion disordered patients $(-1.1<z<-12.3, p<.0007$, for the remaining comparisons). The dissociative patients revealed the highest DES scores, followed by conversion disordered patients, then patients suffering from PTSD, somatization, and anxiety and depression; the nonclinical subjects had the lowest scores. In the SDQ-20, conversion disordered patients had the highest scores, followed by dissociative and PTSD patients, somatization patients, and then patients suffering from anxiety and depression; nonclinical subjects again scored the lowest $(-0.1$ $<z<-8.9, p<.0007$, for significant comparisons). The Mann-Whitney test revealed that differences did not attain significance in the following comparisons of patients: dissociative disorders versus PTSD, dissociative disorders versus conversion disorders, dissociative disorders versus somatization disorders, and PTSD and conversion disorders.

Table 3 shows the results of the comparisons of psychopathological symptoms between men and women found using the Kruskal-Wallis oneway analysis of variance (the equality of variance was not assumed for depression). Women reported significantly more symptoms of somatization, 
TABLE 2. Differences between several psychopathological disorders on the dissociative Experiences Scale (DES) and on the Somatoform Dissociation Questionnaire (SDQ-20).

\begin{tabular}{lcccccrrr}
\hline Measure & $\begin{array}{c}\text { Dissociative } \\
\text { Disorders }\end{array}$ & PTSD & $\begin{array}{c}\text { Conversion } \\
\text { Disorder }\end{array}$ & $\begin{array}{c}\text { Somatization } \\
\text { Disorder }\end{array}$ & $\begin{array}{c}\text { Anxiety and } \\
\text { Depression } \\
\text { Disorders }\end{array}$ & Nonclinical & Kruskal-Wallis $H$ & $p$ \\
\hline DES Score & $39.2(12.4)$ & $35.0(13.5)$ & $38.4(14.2)$ & $19.0(10.4)$ & $18.3(10.1)$ & $9.3(6.0)$ & 246.8 \\
SDQ Score & $39.1(11.7)$ & $39.0(11.8)$ & $39.5(14.0)$ & $31.8(9.2)$ & $28.8(6.6)$ & $23.2(4.0)$ & 181.1 & $<.001$ \\
\hline
\end{tabular}

Notes: Data are $M(S D)$, except where noted. PTSD = posttraumatic stress disorder.

Significant post hoc Mann-Whitney pairwise comparisons $(p<.0007$, Bonferroni-corrected; other comparisons nonsignificant):

DES: Dissociative > Somatization, Dissociative > Anxiety and Depression, Dissociative > Nonclinical; PTSD > Somatization, PTSD > Anxiety and Depression, PTSD > Nonclinical, Conversion > Somatization, Conversion > Anxiety and Depression, Conversion > Nonclinical, Somatization > Nonclinical.

SDQ: Dissociative > Somatization, Dissociation > Anxiety and Depression, Dissociation > Nonclinical, PTSD > Somatization, PTSD > Anxiety and Depression, PTSD > Nonclinical, Conversion > Anxiety and Depression, Conversion > Nonclinical; Somatization > Nonclinical. 
TABLE 3. Comparisons of psychopathological symptoms (BSI Subscales) between women and men in clinical and nonclinical samples.

\begin{tabular}{lcccc}
\hline BSI Subscale & Women, $M(S D)$ & Men, $M(S D)$ & Kruskal-Wallis $H$ & $p$ \\
\hline Global Severity Index & $1.2(0.7)$ & $1.0(0.7)$ & 15.0 & .000 \\
Somatization & $1.0(0.8)$ & $0.7(0.8)$ & 16.2 & .000 \\
Interpersonal Sensitivity & $1.4(0.8)$ & $1.1(0.9)$ & 12.6 & .000 \\
Anxiety & $1.3(0.8)$ & $1.0(0.8)$ & 14.5 & .000 \\
Phobic Anxiety & $0.8(0.8)$ & $0.6(0.8)$ & 7.0 & .008 \\
Obsessive Compulsion & $1.5(0.8)$ & $1.3(0.7)$ & 9.2 & .002 \\
Depression & $1.4(0.8)$ & $1.0(0.8)$ & 16.2 & .000 \\
Hostility & $1.1(0.8)$ & $1.0(0.7)$ & 1.8 & .174 \\
Paranoid Ideation & $1.4(0.8)$ & $1.2(0.8)$ & 6.9 & .008 \\
Psychoticism & $1.1(0.8)$ & $0.8(0.7)$ & 10.5 & .001 \\
\hline
\end{tabular}

Notes: BSI = Brief Symptom Inventory.

interpersonal sensitivity, anxiety, phobic anxiety, obsessive compulsion, depression, paranoid ideation, and psychoticism than men, but they did not display more hostility symptoms $(p<.01)$.

The other demographic categories also showed significant differences. The younger subjects (18-29 years) revealed significantly more symptoms of interpersonal sensitivity, anxiety, phobic anxiety, obsessive compulsion, depression, and hostility $(p<.05)$. Subjects who were single showed significantly more symptoms of interpersonal sensitivity, anxiety, phobic anxiety, obsessive compulsion, depression, paranoia, psychoticism, and hostility $(p<.01)$. Finally, less educated subjects showed significantly more symptoms of somatization and depression $(p<.05)$.

\section{Factors Associated with High versus Low Dissociation (Psychological and Somatoform)}

Using multiple logistic regression we found that both men and women were more likely to have pathological psychological dissociation when they had a combination of symptoms of paranoid ideation, psychoticism, and depression. Men were more vulnerable to psychological dissociation when they had symptoms of obsession and paranoid ideation, and women when they had symptoms of psychoticism and paranoid ideation.

Women with less education were more likely to have pathological somatoform dissociation. The symptoms of somatization and psychoticism 
TABLE 4. Multiple regression analysis of psychopathological factors associated with pathological dissociation (psychological and somatoform) among clinical and nonclinical subjects $(N=505)$ in a portuguese sample.

\begin{tabular}{|c|c|c|c|c|c|c|c|c|c|c|c|c|}
\hline \multirow[t]{2}{*}{ Variable } & \multicolumn{2}{|c|}{$D E S \geq 30$} & \multicolumn{2}{|c|}{ DES $\geq 30$ (Men) } & \multicolumn{2}{|c|}{ DES $\geq 30$ (Women) } & \multicolumn{2}{|c|}{$S D Q \geq 35$} & \multicolumn{2}{|c|}{$S D Q \geq 35$ (Men) } & \multicolumn{2}{|c|}{$S D Q \geq 35$ (Women) } \\
\hline & OR & $95 \% \mathrm{Cl}$ & OR & $95 \% \mathrm{Cl}$ & OR & $95 \% \mathrm{Cl}$ & OR & $95 \% \mathrm{Cl}$ & OR & $95 \% \mathrm{Cl}$ & OR & $95 \% \mathrm{Cl}$ \\
\hline Somatization & 0.77 & $0.45-1.30$ & 0.99 & $0.31-3.14$ & 1.23 & $0.66-2.40$ & $2.66^{*}$ & $1.60-4.41$ & $3.23^{*}$ & $0.98-10.58$ & $2.28^{*}$ & $1.27-4.11$ \\
\hline $\begin{array}{c}\text { Interpersonal } \\
\text { Sensitivity }\end{array}$ & 1.46 & $0.76-2.80$ & 1.02 & $0.24-4.34$ & 0.84 & $0.37-1.91$ & 1.06 & $0.58-1.95$ & 2.23 & $0.58-8.63$ & 0.87 & $0.43-1.77$ \\
\hline Anxiety & 0.76 & $0.35-1.65$ & 0.79 & $0.17-3.66$ & 1.41 & $0.53-3.76$ & 1.07 & $0.53-2.16$ & 0.84 & $0.18-4.00$ & 1.37 & $0.58-3.23$ \\
\hline Phobic Anxiety & 1.11 & $0.64-1.93$ & 3.30 & $0.95-11.46$ & 0.73 & $0.37-1.45$ & 0.99 & $0.59-1.68$ & 1.17 & $0.38-3.62$ & 0.85 & $0.45-1.59$ \\
\hline $\begin{array}{l}\text { Obsessive } \\
\text { Compulsion }\end{array}$ & 0.61 & $0.30-1.23$ & $0.83^{*}$ & $0.16-4.29$ & 4.96 & $2.00-12.28$ & 0.94 & $0.47-1.87$ & 0.22 & $0.04-1.31$ & 1.28 & $0.58-2.80$ \\
\hline Depression & $1.92^{*}$ & $1.05-3.48$ & 6.32 & $1.54-25.00$ & 1.05 & $0.44-2.50$ & 0.93 & $0.54-1.58$ & 0.43 & $0.09-2.06$ & 0.96 & $0.53-1.74$ \\
\hline Hostility & 0.88 & $0.55-1.41$ & 0.24 & $0.04-1.26$ & 0.61 & $0.31-1.22$ & 1.33 & $0.83-2.13$ & 1.85 & $0.68-5.00$ & 1.25 & $0.72-2.17$ \\
\hline $\begin{array}{l}\text { Paranoid } \\
\text { Ideation }\end{array}$ & $.33^{*}$ & $0.18-0.61$ & 0.90 & $0.36-2.22$ & 1.07 & $0.60-1.91$ & 1.33 & $0.76-2.31$ & 2.71 & $0.72-10.21$ & 1.24 & $0.65-2.35$ \\
\hline Psychoticism & $0.29^{*}$ & $0.14-0.60$ & $3.50^{*}$ & $1.03-11.83$ & 2.78 & $1.32-5.87$ & $2.59^{*}$ & $1.29-5.16$ & $8.39^{*}$ & $1.40-50.35$ & 1.96 & $0.90-4.28$ \\
\hline
\end{tabular}

Notes: DES = Dissociative Experiences Scale; SDQ = Somatoform Dissociation Questionnaire; OR = odds ratio; $\mathrm{Cl}=\mathrm{confidence} \mathrm{interval}$. ${ }^{*} p<.05$. 
TABLE 5. Multiple regression analysis of demographic factors associated with pathological psychological dissociation (DES $\geq 30$ ) and pathological somatoform dissociation (SDQ $\geq 35$ ) among clinical and nonclinical subjects $(N=505)$ in a portuguese sample.

\begin{tabular}{|c|c|c|c|c|}
\hline \multirow[t]{2}{*}{ Variable } & \multicolumn{2}{|c|}{$\begin{array}{c}\text { Pathological Psychological } \\
\text { Dissociation }\end{array}$} & \multicolumn{2}{|c|}{$\begin{array}{c}\text { Pathological Somatoform } \\
\text { Dissociation }\end{array}$} \\
\hline & OR & $95 \% \mathrm{Cl}$ & OR & $95 \% \mathrm{Cl}$ \\
\hline \multicolumn{5}{|l|}{ Gender } \\
\hline Male & $0.57^{*}$ & $0.34-0.95$ & $0.51^{*}$ & $0.32-0.80$ \\
\hline Female & $1.75^{\star}$ & $1.05-2.92$ & $1.97^{*}$ & $1.25-3.12$ \\
\hline Age & $0.94^{*}$ & $0.91-0.97$ & 0.20 & $0.68-6.14$ \\
\hline Years of Education & $0.93^{*}$ & $0.87-1.00$ & $0.86^{*}$ & $0.81-0.92$ \\
\hline \multicolumn{5}{|l|}{ Marital Status } \\
\hline Married & 1.10 & $0.57-2.13$ & 1.22 & $0.68-2.22$ \\
\hline Single & 0.91 & $0.47-1.74$ & 0.82 & $0.45-1.48$ \\
\hline
\end{tabular}

Notes: $\mathrm{DES}=$ Dissociative Experiences Scale; SDQ = Somatoform Dissociation Questionnaire; $\mathrm{OR}=$ odds ratio; $\mathrm{Cl}=$ confidence interval.

${ }^{*} p<.05$.

were significantly associated with pathological somatoform dissociation for both men and women. Men were more vulnerable to pathological somatoform dissociation when they had symptoms of somatization and psychoticism, and women when they had symptoms of somatization (Table 4). Higher psychological dissociation was significantly more frequent in women, in the youngest of the subjects, and in those with less education (Table 5).

\section{DISCUSSION}

This study focuses on demographic variables and mental health in the dissociation variation of a Portuguese sample. The mean scores of the DES $(9.3 \pm 6)$ and SDQ-20 (23.2 \pm 4.00$)$ were comparable to those in other investigations. The major studies of psychopathological dissociation in countries other than Canada or the United States were performed in representative samples of the general population and estimated similar mean scores: In Finland the mean was 8.0 \pm 8.1 (Maaranen, Tanskanen, 
Honkalampi, et al., 2005), in Germany $2.3 \pm 4.2$, in The Netherlands $10.4 \pm 9.6$ (Modestin \& Erni, 2004), and in Turkey 6.7 \pm 6.1 . The studies of somatoform dissociation in general populations are fewer: Finland had a mean of $23.3 \pm 6.1$ (Maaranen et al., 2004), The Netherlands a range between $23.20 \pm 4.97$ and $24.43 \pm 4.36$ (Näring \& Nijenhuis, 2005), and Turkey $27.4 \pm 8.2$ (Sar et al., 2000). This indicates that both types of dissociation are stable constructs across cultures.

The main objective of our study was to explore which factors were associated with dissociation. In relation to psychological dissociation, symptoms of paranoid ideation, psychoticism, and depression were significantly associated with high psychological dissociation in both men and women; men with high dissociation had more symptoms of obsession and paranoid ideation, and women had more symptoms of psychoticism and paranoid ideation. Some studies support the relationship between dissociation and psychoticism (Allen et al., 1996; Kennedy et al., 2004; H. Merckelbach et al., 2000; Moskowitz et al., 2005; C. Spitzer et al., 2006), between dissociation and paranoid ideation (Moskowitz et al., 2005), and between dissociation and symptoms of obsession (Grabe et al., 1999; Prueter et al., 2002; Rufer et al., 2006). We found a negative relationship between age and dissociation, which is consistent with what other investigators have found (Näring \& Nijenhuis, 2005; Seedat et al., 2003; C. Spitzer et al., 2006). Our findings did not sustain the association between marital status and dissociation; this contradicts some studies (Maaranen, Tanskanen, Kaisa, et al., 2005; Seedat et al., 2003; C. Spitzer et al., 2006). Educational level was negatively associated with dissociation; there was a similar trend in a substance abuse study (Dunn et al., 1993).

Factors associated with high somatoform dissociation were symptoms of somatization and psychoticism for men, symptoms of somatization for women, and symptoms of somatization and psychoticism for both men and women. The association with symptoms of somatization is supported by a previous study (Nijenhuis et al., 1999). Age was not associated with somatoform dissociation; the majority of the studies support this finding, with the exception of two (Maaranen et al., 2004; Sar et al., 2000). Lower educational level was associated with higher dissociation; similar findings were reported in two studies (Maaranen et al., 2004; Sar et al., 2000). Marital status had no significant relationship with somatoform dissociation.

The association between psychological dissociation and psychoticism and between psychological dissociation and paranoid ideation is under discussion. Some investigations indicate that traumatic etiology may contribute to both psychotic-like experiences and dissociation (Irwin, 2001); 
others point to sleep disturbances as common grounds for both dissociative and schizotypal features (M. Merckelbach \& Giesbrecht, 2006).

Our study was not intended to explore primarily the association between dissociation and psychiatric disorders; nevertheless, we should note that patients with dissociative disorders and conversion disorders reported higher dissociation levels, followed by those diagnosed with PTSD. This finding is similar to the International Classification of Diseases-10 (World Health Organization, 1992) categorization, where conversion disorders, but not somatization disorder, are classified as dissociative. C. Spitzer, Spelsberg, Grabe, Mundt, and Freyberger (1999) and Nemiah (1993) also suggested that conversion disorders be regrouped with the dissociative disorders in the DSM.

The inclusion of a clinical and a nonclinical control sample, and various clinical groups, were strong points of our study. However, our clinical sample included more women, and they had more psychopathological symptoms; a more balanced sample could have given different results for associations between dissociation and the analyzed factors. We should interpret with care the fact that subjects with lower educational levels reported higher dissociation, because difficulties in comprehension may have contributed to that.

Finally, some notes of caution are required due to methodological aspects. A limitation, as C. Spitzer et al. (2006) pointed out, was the use of cutoff thresholds for determination of pathological psychological dissociation. This methodology is not universally used; G. Waller, Ohanian, Meyer, Everill, and Rouse (2001) and Seedat et al., (2003) employed it, but others have used a categorical DES taxon (Simeon, Knutelska, Nelson Guralnik, \& Schmeidler, 2003; C. Spitzer et al., 2006). Another methodological constraint is that we used the entire DES scale, including items of nonpathological dissociation.

A highly structured interview such as the Dissociative Disorders Interview Schedule reduces and controls the implicit assumptions of the interviewers. However, we did not use the structured interview for the assessment of dissociative symptoms in all patients. The use of the LEAD procedure could be a strongpoint of our study, but some consider that this methodology has flaws (Kranzler, Tennen, Babor, Kadden, \& Rounsaville, 1997). As with most studies in this field, a constraint of our study was its cross-sectional nature, which prevented us from establishing causal relationships.

To conclude, it would be valuable to investigate the prevalence, etiology, and correlates of pathological dissociation in representative, balanced, and randomized samples from different cultures. This is an 
important issue, as cross-cultural comparisons are now possible because reliable screening instruments have been constructed and adapted for use in various countries. In order to control for cultural aspects, comparable measures, samples, and procedures are required.

\section{REFERENCES}

Akyüz, G., Doğan, O., Sar, V., Yargic, L. I., \& Tutkun, H. (1999). Frequency of dissociative identity disorder in the general population in Turkey. Comprehensive Psychiatry, 40, 151-159.

Allen, J. G., Coyne, L., \& Console, D. A. (1996). Dissociation contributes to anxiety and psychoticism on the Brief Symptom Inventory. Journal of Nervous and Mental Disease, 184, 639-644.

American Psychiatric Association. (1994). Diagnostic and statistical manual of mental disorders (4th ed.). Washington, DC: Author.

Baker, D., Hunter, E., Lawrence, E., Medford, N., Patel, M., Senior, C., et al. (2003). Depersonalisation disorder: Clinical features of 204 cases. British Journal of Psychiatry, $182,428-433$.

Bernstein, E. M., \& Putnam, F. W. (1986). Development, reliability and validity of a dissociation scale. Journal of Nervous and Mental Disease, 174, 727-735.

Boon, S., \& Draijer, N. (1991). Diagnosing dissociative disorders in the Netherlands: A pilot study with the structured interview for $D S M-I I I-R$ dissociative disorders. American Journal of Psychiatry, 148, 458-462.

Bremner, J. D., Southwick, S., Brett, E., Fontana, A., Rosenheck, R., \& Charney, D. S. (1992). Dissociation and post-traumatic stress disorder in Vietnam combat veterans. American Journal of Psychiatry, 149, 328-332.

Canavarro, M. C. (1988). Inventário de Sintomas psicopatológicos [Psychopathological symptom inventory]. In M. R. Simões, M. M. Gonçalves, \& L. S. Almeida (Eds.), Testes e provas psicológicas em Portugal [Pychological tests and tasks in Portugal]. (Vol. 26, pp. 95-109). Braga, Portugal: Apport.

Carlson, E. B., \& Putnam, F. W. (1993). An update of the Dissociative Experiences Scale. Dissociation, 6(1), 16-27.

Carlson, E. B., Putnam, F. W., Ross, C. A., Torem, M., Coons, P., Dill, D. L., et al. (1993). Validity of the Dissociative Experiences Scale in screening for multiple personality disorder: A multicenter study. American Journal of Psychiatry, 150, 1030-1036.

Dorahy, M. J., Lewis, C. A., Millar, R. G., \& Gee, T. L. (2003). Predictors of nonpathological dissociation in Northern Ireland: The affects of trauma and exposure to political violence. Journal of Traumatic Stress, 16, 611-615.

Dunn, G. E., Paolo, A. M., Ryan, J. J., \& Van Fleet, J. (1993). Dissociative symptoms in a substance abuse population. American Journal of Psychiatry, 150, 1043-1047.

El-Hage, W., Darves-Bornoz, J.-M., Allilaire, J.-F., \& Gaillard, P. (2002). Posttraumatic somatoform dissociation in French psychiatric outpatients. Journal of Trauma \& Dissociation, 3(3), 59-74. 
Espirito-Santo, H. A., Madeira, F., \& Pio Abreu, J. L. (2007). Versão Portuguesa do Dissociative Disorders Interview Schedule (DDIS-P). Estudo preliminar de adaptação a uma amostra da população Portuguesa [Portuguese version of the DDIS-P. Preliminary adaptation study to a Portuguese Sample]. Revista de Psiquiatria Clínica, 28, 5-17.

Espirito Santo, H. A., \& Pio Abreu, J. L. (in press). Portuguese validation of Dissociative Experiences Scale (DES). Journal of Trauma \& Dissociation.

Espirito Santo, H. A., \& Pio Abreu, J. L. (2006). Psychiatric symptoms and dissociation in conversion disorders, somatization disorder, and dissociative disorders. Manuscript submitted for publication.

Espirito Santo, H. A., \& Pio Abreu, J. L. (2007). Dissociative disorders and other psychopathological groups: Exploring the differences through Somatoform Dissociation Questionnaire (SDQ-20). Revista Brasileira de Psiquiatria, 29, 354-358.

Grabe, H. J., Goldschmidt, F., Lehmkuhl, L., Gansicke, M., Spitzer, C., \& Freyberger, H. J. (1999). Dissociative symptoms in obsessive-compulsive dimensions. Psychopathology, 32(6), 319-324.

Irwin, H. J. (1999). Pathological and nonpathological dissociation: The relevance of childhood trauma. Journal of Psychology, 133, 157-164.

Irwin, H. J. (2001). The relationship between dissociative tendencies and schizotypy: An artifact of childhood trauma? Journal of Clinical Psychology, 57, 331-342.

Janet, P. (1998). L'Automatisme psychologique [The psychological automatism]. Paris: Odile Jacob. (Original work published 1889).

Kennedy, F., Clarke, S., Stopa, L., Bell, L., Rouse, H., Ainsworth, C., et al. (2004). Towards a cognitive model and measure of dissociation. Journal of Behavior Therapy \& Experimental Psychiatry, 35, 25-48.

Kranzler, H. R., Tennen, H., Babor, T. F., Kadden, R. M., \& Rounsaville, B. J. (1997). Validity of the longitudinal, expert, all data procedure for psychiatric diagnosis in patients with psychoactive substance use disorders. Drug and Alcohol Dependence, 45, 93-104.

Loewenstein, R. J. (1991). An office mental status examination for complex chronic dissociative symptoms and multiple personality disorder. Psychiatric Clinics of North America, 14, 567-604.

Maaranen, P., Tanskanen, A., Haatainen, K., Koivumaa-Honkanen, H., Hintikka, J., \& Viinamäki, H. (2004). Somatoform dissociation and adverse childhood experiences in the general population. Journal of Nervous and Mental Disease, 192, 337-342.

Maaranen, P., Tanskanen, A., Honkalampi, K., Haatainen, K., Hintikka, J., \& Viinamäki, H. (2005). Factors associated with pathological dissociation in the general population. Australian and New Zealand Journal of Psychiatry, 39, 387-394.

Maaranen, P., Tanskanen, A., Kaisa, H., Honkalampi, K., Koivumaa-Honkanen, H., Hintikka, J., et al. (2005). The relationship between psychological and somatoform dissociation in the general population. Journal of Nervous and Mental Disease, 193, 690-692.

Merckelbach, H., Rassin, E., \& Muris, P. (2000). Dissociation, schizotypy, and fantasy proneness in undergraduate students. Journal of Nervous and Mental Disease, 188, 428-431.

Merckelbach, M., \& Giesbrecht, T. (2006). Subclinical dissociation, schizotypy, and traumatic distress. Personality and Individual Differences, 40, 365-374. 
Modestin, J., \& Erni, T. (2004). Testing the dissociative taxon. Psychiatry Research, $126(1), 77-82$.

Moskowitz, A. K., Barker-Collo, S., \& Ellson, L. (2005). Replication of dissociationpsychosis link in New Zealand students and inmates. Journal of Nervous and Mental Disease, 193, 722-727.

Näring, G., \& Nijenhuis, E. R. S. (2005). Relationships between self-reported potentially traumatizing events, psychoform and somatoform dissociation, and absorption, in two non-clinical populations. Australian and New Zealand Journal of Psychiatry, 39, 982-988.

Nemiah, J. C. (1993). Dissociation, conversion, and somatization. In D. Spiegel, R. P. Kluft, R. J. Loewenstein, J. C. Nemiah, F. W. Putnam, \& M. Steinberg (Eds.), Dissociative disorders: A clinical review (pp. 104-116). Lutherville, MD: Sidran Press.

Nijenhuis, E. R. S. (2000). Somatoform dissociation: Major symptoms of dissociative disorders. Journal of Trauma \& Dissociation, 1(4), 7-32.

Nijenhuis, E. R. S., Spinhoven, P., Van Dyck, R., Van der Hart, O., \& Vanderlinden, J. (1996). The development and psychometric characteristics of the Somatoform Dissociation Questionnaire (SDQ-20). Journal of Nervous and Mental Disease, 184, 688-694.

Nijenhuis, E. R. S., Van der Hart, O., \& Kruger, K. (2002). The psychometric characteristics of the Traumatic Experiences Checklist (TEC): First findings among psychiatric outpatients. Clinical Psychology and Psychotherapy, 9, 200-210.

Nijenhuis, E. R. S., Van Dyck, R., Spinhoven, P., Van der Hart, O., Chatrou, M., Vanderlinden, J., et al. (1999). Somatoform dissociation discriminates among diagnostic categories over and above general psychopathology. Australian and New Zealand Journal of Psychiatry, 33, 511-520.

Norton, G. R., Ross, C. A., \& Novoltny, M. (1990). Factors that predict scores on the Dissociative Experiences Scale. Journal of Clinical Psychology, 46, 273-278.

Pribor, E. F., Yutzy, S. H., Dean, J. T., \& Wetzel, R. D. (1993). Briquet's syndrome, dissociation, and abuse. American Journal of Psychiatry, 150, 1507-1511.

Prueter, C., Schultz-Venrath, U., \& Rimpau, W. (2002). Dissociative and associated psychopathological symptoms in patients with epilepsy, pseudoseizures, and both seizure forms. Epilepsia, 43(2), 188-192.

Ross, C. A., Heber, S., Norton, G. R., Anderson, G., Anderson, D., \& Barchet, P. (1989). The Dissociative Disorders Interview Schedule: A structured interview. Dissociation, 2(3), 169-189.

Ross, C. A., Joshi, S., \& Currie, R. (1990). Dissociative experiences in the general population. American Journal of Psychiatry, 147, 1547-1552.

Rufer, M., Fricke, S., Held, D., Cremer, J., \& Hand, I. (2006). Dissociation and symptom dimensions of obsessive-compulsive disorder. A replication study. European Archives of Psychiatry and Clinical Neuroscience, 256(3), 146-150.

Sar, V., Kundakçı, T., Kızıltan, E., Bakim, B., \& Bozkurt, O. (2000). Differentiating dissociative disorders from other diagnostic groups through somatoform dissociation in Turkey. Journal of Trauma \& Dissociation, 1(4), 67-80.

Saxe, G. N., Van der Kolk, B. A., Berkowitz, R., Chinman, G., All, K., Lieberg, G., et al. (1993). Dissociative disorders in psychiatric inpatients. American Journal of Psychiatry, 150, 1037-1042. 
Saxe, G. N., Chinman, G., Berkowitz, R., Hall, K., Lieberg, G., Schwartz, J., et al. (1994). Somatization in patients with dissociative disorders. American Journal of Psychiatry, $151,1329-1334$.

Seedat, S., Stein, M. B., \& Forde, D. R. (2003). Prevalence of dissociative experiences in a community sample: Relationship to gender, ethnicity, and substance use. Journal of Nervous and Mental Disease, 191, 115-120.

Shearer, S. L. (1994). Dissociative phenomena in women with borderline personality disorder. American Journal of Psychiatry, 151, 1324-1328.

Simeon, D., Knutelska, M., Nelson, D., Guralnik, O., \& Schmeidler, J. (2003). Examination of the pathological dissociation taxon in depersonalization disorder. Journal of Nervous and Mental Disease, 191, 738-744.

Spitzer, C., Barnow, S., Grabe, H.-J., Klauer, T., Stieglitz, R.-D., Schneider, W., et al. (2006). Frequency, clinical and demographic correlates of pathological dissociation in Europe. Journal of Trauma \& Dissociation, 7(1), 51-56.

Spitzer, C., Klauer, T., Grabe, H.-J., Lucht, M., Stieglitz, R.-D., Schneider, W., et al. (2003). Gender differences in dissociation, a dimensional approach. Psychopathology, 36(2), 65-70.

Spitzer, C., Spelsberg, B., Grabe, H. J., Mundt, B., \& Freyberger, H. J. (1999). Dissociative experiences and psychopathology in conversion disorders. Journal of Psychosomatic Research, 46(3), 291-294.

Spitzer, C., Willert, C., Grabe, H.-J., Rizos, T., Möller, B., \& Freyberger, H. J. (2004). Dissociation, hemispheric asymmetry, and dysfunction of hemispheric interaction: A transcranial magnetic stimulation approach. Journal of Neuropsychiatry Clinical Neuroscience, 16(2), 163-169.

Spitzer, R. L. (1983). Psychiatric diagnosis: Are clinicians still necessary? Comprehensive Psychiatry, 24, 399-411.

Tezcan, E., Atmaca, M., Kuloglu, M., Gecici, O., Buyukbayram, A., \& Tutkun, H. (2003). Dissociative disorders in Turkish inpatients with conversion disorder. Comprehensive Psychiatry, 44, 324-330.

Tutkun, H., Sar, V., Yargic, L. I., Ozpulat, T., Yanik, M., \& Kiziltan, E. (1998). Frequency of dissociative disorders among psychiatric inpatients in a Turkish university clinic. American Journal of Psychiatry, 155, 800-805.

Van der Hart, O., Van Dijke, A., Van Son, M. J. M., \& Steele, K. (2000). Somatoform dissociation in traumatized World War I combat soldiers: A neglected clinical heritage. Journal of Trauma \& Dissociation, 1(4), 33-66.

Vanderlinden, J., Vandereycken, W., Van Dyck, R., \& Vertommen, H. (1993). Dissociative experiences and trauma in eating disorder. International Journal of Eating Disorders, 13(2), 187-193.

Walker, E. A., Katon, W. J., Neraas, K., Jemelka, R. P., \& Massoth, D. (1992). Dissociation in women with chronic pelvic pain. American Journal of Psychiatry, 149, 534-537.

Waller, G., Hamilton, K., Elliot, P., Lewendon, J., Stopa, L., Waters, A., et al. (2000). Somatoform dissociation, psychological dissociation, and specific forms of trauma. Journal of Trauma \& Dissociation, 1(4), 81-98.

Waller, G., Ohanian, V., Meyer, C., Everill, J., \& Rouse, H. (2001). The utility of dimensional and categorical approaches to understanding dissociation in the eating disorders. British Journal of Clinical Psychology, 40, 387-397. 
Waller, N. G., \& Ross, C. A. (1997). The prevalence and biometric structure of pathological dissociation in the general population: Taxometric and behavior genetic findings. Journal of Abnormal Psychology, 106, 499-510.

World Health Organization. (1992). The ICD-10 classification of mental and behavioural disorders, clinical descriptions and diagnostic guidelines. Geneva, Switzerland: Author.

RECEIVED: $11 / 27 / 06$

REVISED: $4 / 27 / 07$

ACCEPTED: 6/15/07 
